\title{
CAMBIOS EN EL COLOR DURANTE EL BENEFICIO DEL GRANO DE CACAO (Theobroma cacao L.) PERUANO PROCEDENTE DE PIURA
}

\author{
Color changes during post harvest of peruvian cocoa beans from Piura \\ Gabriela C. Chire ${ }^{1}$, Piero A. Verona ${ }^{1}$, Jorge H. Guzmán ${ }^{2}$
}

${ }^{1}$ Facultad de Industrias Alimentarias, Universidad Nacional Agraria La Molina. ${ }^{2}$ Facultad de Farmacia y Bioquímica, Universidad Nacional Mayor de San Marcos

\section{RESUMEN}

Se estudió la relación de los valores que integran el color del grano de cacao durante los procesos de fermentación, secado y tiempo de cosecha, a un mismo tiempo de aguante en mazorca de cacao. Se utilizó el sistema de evaluación CIELAB, que define al color como índice físico y modelo cromático; se midieron los componentes del color $\left(L^{*}, a^{*}\right.$ y $\left.b^{*}\right)$ y se calculó la variación del color $\left(\Delta E^{*}\right)$ a medida que se dieron los cambios bioquímicos durante la fermentación y el secado en el grano de cacao Cultivar Nativo de Piura. Los valores promedio del color comprendieron para $L^{*}$ de 52,03 a 34,05, $a^{*}$ de 12,64 a 14,69 y $b^{*}$ de 12,59 a 5,15, sin variación significativa en la fermentación del grano durante su beneficio. Se concluye que $\Delta E^{*}$ es diferente en el secado para ambos tiempos de cosecha $(p<0,05)$ debido a las condiciones climáticas.

Palabras clave: beneficio del grano de cacao, cambios en el color, componentes del color.

\section{SUMMARY}

Through this research which aim is to relate the color variations of cocoa beans during the fermentation, drying and harvest time process, in an iqual time of cocoa pods storage. Was used for this evaluation the CIELAB system, which define the color as physical index and color model $\left(L^{*}, a^{*}\right.$ and $\left.b^{*}\right)$, then was calculated color change $\left(\Delta E^{*}\right)$, at measure were giving the biochemical changes during the fermentation and drying process in cocoa beans of Cultivar Nativo from Piura. The average values of color for $L^{*}$ were 52,03 to 34,$05 ; a^{*}$ were 12,64 to 14,69 and for $b^{*}$ were 12,59 to 5,15 being variance non-significative for fermentation process of Cultivar Nativo cocoa beans during post-harvest. It is concluded $\Delta E^{*}$ is different in drying for both harvest time $(\mathrm{p}<0,05)$ due to climatic conditions.

Keywords: cocoa bean post-harvest, color compounds, color changes.

\section{INTRODUCCIÓN}

E l cacao es un cultivo originario de la región tropical húmeda de la selva Amazónica, actualmentees un productodeimportancia mundial, y los granos secos (beneficiados) son exportados a muchos países. Las series de operaciones a realizar, necesarias para obtener el grano del cacao con destino a la producción de chocolates, se inicia con la recolección de mazorcas maduras y se continúa con la extracción del cacao en baba, fermentación, secado, selección y posterior procesamiento ${ }^{(1)}$.

En el beneficio del cacao (Theobroma cacao L.), la fermentación y el secado son etapas de gran importancia. El proceso de fermentación se desarrolla en dos etapas. La primera es anaerobia, se desarrollan las levaduras y a la vez bacterias acido lácticas. Estas bacterias predominan durante el segundo día de fermentación, y su población disminuye cuando las condiciones del medio se vuelven aerobias al introducir aire a la masa por la remoción del grano de un contenedor a otro ${ }^{(2)}$. La presencia de ácido láctico no es favorable para la calidad del cacao, ya que difunde al interior del grano y permanece en éste hasta la manufactura del chocolate, generando un sabor ácido desagradable que puede enmascarar el sabor del chocolate, según lo manifestado por Thompson et al., citado por Rodríguez (3). La segunda parte es aerobia, inducida por la remoción de los granos de cacao, favoreciendo la proliferación de las bacterias acido acéticas. Estas bacterias oxidan el etanol producidodurantela fermentaciónalcohólicaaácidoacético y acetato de etilo. Esta reacción es altamente exotérmica, lo cual genera un aumento en la temperatura de la masa del grano que puede llegar hasta los $50^{\circ} \mathrm{C}$ (2). Thompson et al. (3), identificaron diferentes especies del género Acetobacter durante la fermentación del cacao. El cacao criollo fermenta más rápidamente que el forastero, tardando el primero de dos a tres días y el segundo de cinco a siete días.

No obstante las condiciones climatológicas, el volumen de la masa y el método aplicado ejercen un papel importante sobre la duración del proceso y pueden causar grandes variaciones ${ }^{(4,5)}$.

En la fermentación se producen cambios bioquímicos que dan origen a los precursores del aroma y sabor a chocolate ${ }^{(6,7)}$, además de determinarse su calidad física y 


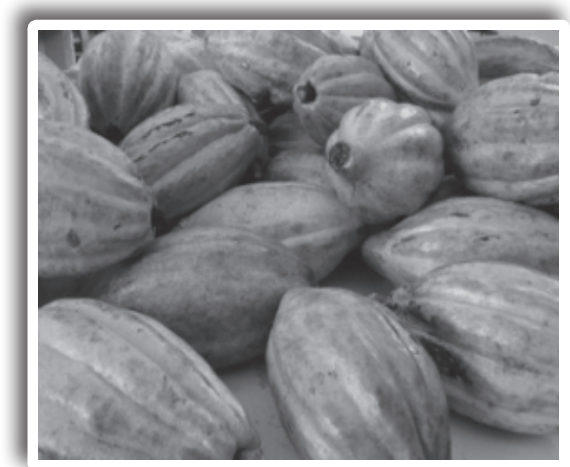

Figura 1. Mazorcas de cacao cultivar nativo de Piura.

química ${ }^{(8)}$. La finalidad de este proceso es obtener un producto estable y de calidad para el comercio, por lo que es uno de los puntos críticos de control durante el beneficio del cacao, puesto que se producen transformaciones bioquímicas notorias que le dan a los granos su sabory aroma característicos.

En la práctica actual, la fermentación se efectúa en cajas especiales de madera, o por el sistema de "montones", donde el líquido azucarado de la pulpa que rodea a los granos es invadido por microorganismos que transforman los azúcares, primero en alcohol y luego en ácido acético mediante la oxidación. La remoción de este mucílago gracias a la intervención de las bacterias facilita el secado.

En el secado el grano obtiene el sabor y aroma a chocolate, por lo que es recomendable que este proceso sea lento durante los dos primeros días. También cambian los colores, apareciendo un tono marrón (café a partir de los compuestos fenólicos $\left.{ }^{(9)}\right)$ típico del cacao fermentado y secado correctamente. Si la temperatura y la velocidad del aire son muy fuertes solo se seca la parte exterior del grano, formándose una corteza dura sobre este_que impide la salida del ácido acético ${ }^{(10)}$, lo que provoca que el cacao tenga mayor acidez.

Finalmente se reduce el exceso de humedad que queda

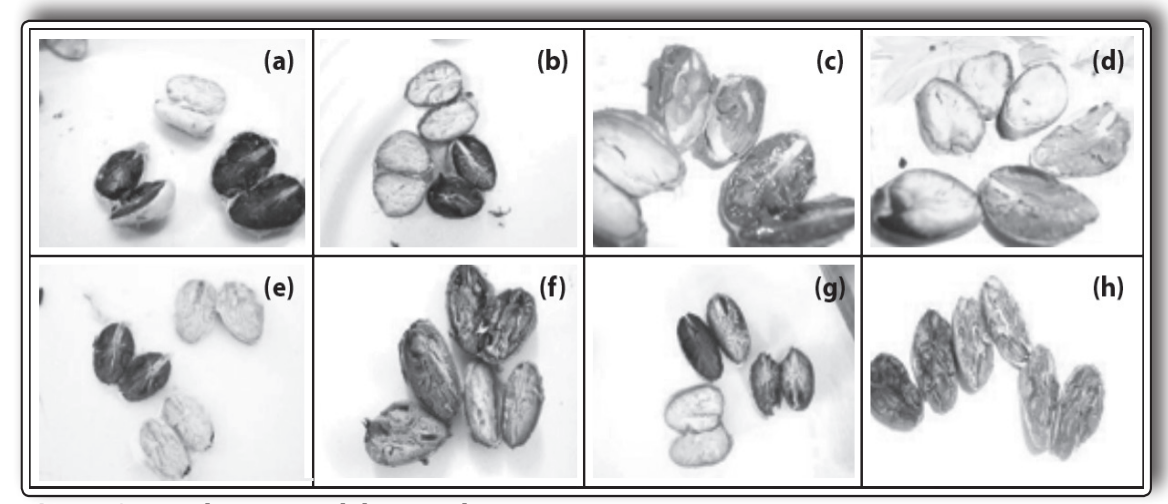

Figura 2. Estado interno del grano de cacao.

1er tiempo cosecha: (a) fermentación inicio, (b) fermentación final, (c) secado inicio, (d) secado final. 2do tiempo cosecha: (e) fermentación inicio, (f) fermentación final, (g) secado inicio, (h) secado final.

Tabla 1. Valores físicos durante la fermentación en ambos tiempos de cosecha.

\begin{tabular}{|c|c|c|c|c|c|c|c|c|c|c|c|c|}
\hline \multirow{3}{*}{ Día } & \multirow{2}{*}{\multicolumn{3}{|c|}{$\begin{array}{c}\text { Temperatura } \\
\text { Masa }\left({ }^{\circ} \mathrm{C}\right)\end{array}$}} & \multirow{2}{*}{\multicolumn{3}{|c|}{$\begin{array}{l}\text { Grosor } \\
\text { (mm) }\end{array}$}} & \multicolumn{6}{|c|}{ pH } \\
\hline & & & & & & & \multicolumn{3}{|c|}{ Cotilendón } & \multicolumn{3}{|c|}{ Testa } \\
\hline & $1^{\mathrm{er}}$ & $2^{\text {do }}$ & Prom & $1^{\mathrm{er}}$ & $2^{\text {do }}$ & Prom & $1^{\mathrm{er}}$ & $2^{\text {do }}$ & Prom & $1^{\mathrm{er}}$ & $2^{\text {do }}$ & Prom \\
\hline 0 & 27,6 & 28,3 & 28,0 & 9,0 & 8,6 & 8,8 & 6,47 & 6,57 & 6,52 & 4,70 & 4,75 & 4,73 \\
\hline 1 & 34,4 & 32,7 & 33,5 & 9,1 & 10,4 & 9,8 & 6,72 & 6,49 & 6,61 & 4,59 & 4,62 & 4,61 \\
\hline 2 & 41,5 & 42,3 & 41,9 & 8,4 & 8,6 & 8,5 & 6,23 & 6,30 & 6,27 & 3,39 & 4,09 & 3,74 \\
\hline 3 & 43,3 & 40,6 & 42,0 & 9,2 & 10,4 & 9,8 & 5,55 & 6,12 & 5,84 & 3,73 & 4,77 & 4,25 \\
\hline
\end{tabular}

Tabla 2. Valores físicos durante el secado solar en ambos tiempos de cosecha.

\begin{tabular}{|c|c|c|c|c|c|c|c|c|c|c|c|c|}
\hline \multirow{3}{*}{ Día } & \multicolumn{6}{|c|}{ Ambiental } & \multirow{2}{*}{\multicolumn{3}{|c|}{$\begin{array}{l}\text { Grosor } \\
(\mathrm{mm})\end{array}$}} & \multirow{2}{*}{\multicolumn{3}{|c|}{$\begin{array}{l}\text { Humedad del } \\
\text { producto }(\mathrm{bh}, \%)\end{array}$}} \\
\hline & \multicolumn{3}{|c|}{ Temperatura ${ }^{\circ} \mathrm{C}$} & \multicolumn{3}{|c|}{ Humedad relativa $(\%)$} & & & & & & \\
\hline & $1^{\mathrm{er}}$ & $2^{\text {do }}$ & Prom & $1^{\mathrm{er}}$ & $2^{\text {do }}$ & Prom & $1^{\mathrm{er}}$ & $2^{\text {do }}$ & Prom & $1^{\mathrm{er}}$ & $2^{\text {do }}$ & Prom \\
\hline 1 & 26,6 & 26,6 & 26,6 & 48,0 & 54,0 & 51,0 & 8,2 & 9,4 & 8,8 & 59,6 & 65,3 & 62,5 \\
\hline 2 & 32,8 & 31,6 & 32,2 & 35,0 & 44,0 & 39,5 & 8,4 & 9,3 & 8,9 & 50,9 & 57,0 & 54,0 \\
\hline 3 & 32,6 & 36,5 & 34,6 & 37,2 & 26,0 & 31,6 & 7,1 & 8,2 & 7,7 & 28,1 & 24,1 & 26,1 \\
\hline 4 & 31,3 & 33,3 & 32,3 & 48,2 & 34,5 & 41,4 & 8,4 & 7,5 & 8,0 & 22,0 & 11,7 & 16,9 \\
\hline 5 & 25,0 & 25,6 & 25,3 & 57,2 & 53,0 & 55,1 & 7,8 & 7,9 & 7,9 & 9,3 & 6,0 & 7,7 \\
\hline
\end{tabular}

Tabla 3. Valores de los componentes del color durante el beneficio en el primer tiempo de cosecha.

\begin{tabular}{cccccc} 
Día & Beneficio & $\boldsymbol{L}^{*}$ & $\boldsymbol{a}^{*}$ & $\boldsymbol{b}^{*}$ & $\boldsymbol{\Delta E}^{*}$ \\
\hline 0,0 & Fermentado & $48,53 \pm 11,16$ & $13,90 \pm 3,38$ & $12,41 \pm 10,71$ & \\
3,0 & Fermentado & $53,01 \pm 6,10$ & $11,03 \pm 0,90$ & $4,74 \pm 5,00$ & 15,6 \\
2,0 & Secado & $60,06 \pm 4,40$ & $8,90 \pm 2,30$ & $11,86 \pm 3,00$ & \\
3,0 & Secado & $50,96 \pm 6,70$ & $12,13 \pm 1,90$ & $12,12 \pm 7,20$ & \\
4,5 & Secado & $44,53 \pm 4,40$ & $12,16 \pm 1,50$ & $11,06 \pm 5,20$ & \\
5,0 & Secado & $31,36 \pm 1,90$ & $15,94 \pm 0,80$ & $2,14 \pm 1,30$ & 31,1 \\
\hline
\end{tabular}

Tabla 4. Valores de los componentes del color durante el beneficio en el segundo tiempo de cosecha.

\begin{tabular}{cccccc}
\hline Día & Beneficio & $\boldsymbol{L}^{*}$ & $\boldsymbol{a}^{*}$ & $\boldsymbol{b}^{*}$ & $\boldsymbol{\Delta E}^{*}$ \\
\hline 0,0 & Fermentado & $55,53 \pm 4,70$ & $11,39 \pm 3,70$ & $12,76 \pm 3,50$ & \\
3,0 & Fermentado & $54,04 \pm 11,70$ & $12,29 \pm 4,30$ & $3,00 \pm 7,40$ & 12,9 \\
2,0 & Secado & $53,27 \pm 1,10$ & $12,14 \pm 0,90$ & $5,55 \pm 2,00$ & \\
3,0 & Secado & $44,84 \pm 3,50$ & $11,75 \pm 0,20$ & $3,69 \pm 3,60$ & \\
4,5 & Secado & $41,08 \pm 5,50$ & $12,79 \pm 0,50$ & $7,65 \pm 5,40$ & \\
5,0 & Secado & $36,74 \pm 5,50$ & $13,44 \pm 2,30$ & $8,15 \pm 4,40$ & 17,4 \\
\hline
\end{tabular}

Tabla 5. Tabla resumen ANOVA mostrando los ratios-F para variaciones del color y $\Delta E^{*}$ en el beneficio del cacao.

\begin{tabular}{ccccc}
\hline Variables & $\boldsymbol{\Delta L}^{*}$ & $\boldsymbol{\Delta \boldsymbol { a } ^ { * }}$ & $\boldsymbol{\Delta \boldsymbol { b } ^ { * }}$ & $\boldsymbol{\Delta \boldsymbol { E } ^ { * }}$ \\
\hline Fermentación & 4,48 & 5,97 & 4,10 & 4,52 \\
Secado & 4,11 & $13,85^{*}$ & $21,09^{*}$ & $15,35^{*}$ \\
\hline
\end{tabular}


después de la fermentación, asegurando que no exceda el $8 \%$ para facilitar el almacenamiento y evitar el desarrollo de mohos que deterioran la calidad ${ }^{(9,11)}$.

La Comisión Internacional de Iluminación (CIE) desarrolló un modelo cromático para describir todos los colores que puede percibir el ojo humano definió un espacio cromático mediante coordenadas cilíndricas de claridad $\left(L^{*}\right)$, además de coordenadas rectangulares $L^{*}$ $a^{*} b^{*(12)}$. La coloración del cotiledón es un carácter típico genético que está asociado al tipo de cacao, puede variar del tipo blanco (criollo), hasta el bien pigmentado (forastero), con diferentes tonalidades y distribución de los colores ${ }^{(1)}$.

Los objetivos del presente trabajo fueron conocer los parámetros de color durante el beneficio del cacao según el sistema de evaluación CIELAB $L^{*}, a^{*} \mathrm{y}$

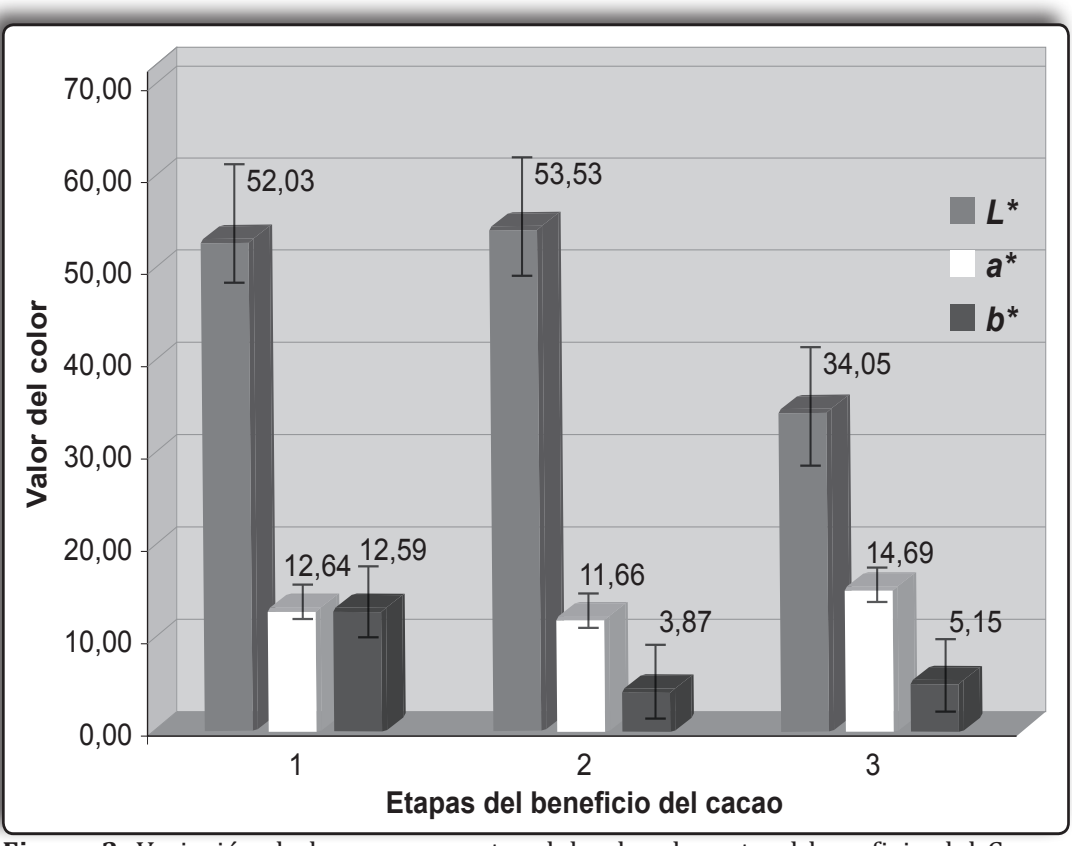

Figura 3. Variación de los componentes del color durante el beneficio del Cacao: (1) fermentación inicio, (2) fermentación final e inicio del secado, (3) secado final. $b^{*}$ e investigar las variaciones de color $\left(\Delta E^{*}\right)$ en cada una de las etapas propias del proceso de beneficio.

\section{MATERIALES Y MÉTODOS}

\section{Diseño de la investigación}

Es una investigación experimental. Se desarrolló el beneficio (fermentación y secado) del cacao en dos tiempos de cosecha, en la que se registraron los cambios de color por el método colorimétrico.

\section{Materia prima}

Mazorcas decacao Cultivar Nativo ${ }^{(13)}$, mezcla degranos tintos y blancos, procedentes del distrito de Chulucanas, provincia de Morropón, departamento de Piura en Perú, cosechados en marzoy abril, con altura de 1500 a 2000 msnm.

\section{Lugar de ejecución}

Las evaluaciones se realizaron en el Laboratorio de Análisis Fisicoquímico de Alimentos de la Facultad de Industrias Alimentarias de la Universidad Nacional Agraria La Molina en Lima, Perú.

\section{Metodología}

Las mazorcas de cacao fueron abiertas para retirar el cacao en baba, iniciando el proceso de beneficio en dos tiempos de cosecha, a un mismo tiempo de aguante en mazorca de cacao. La variable independiente fue el proceso de beneficio (fermentación y secado) y la dependiente la variación del color $\left(\Delta E^{*}\right)$ :

Materiales: placas de metal, desecador devidrio con agente deshidratante, espátulas, magneto, bolsas de polipropileno, material de vidrio, vernier Mitutoyo $^{\circledR}$, termómetro infrarrojo, termohigrómetro, cajas de madera tornillo de 15 X 15 X $15 \mathrm{~cm}$ (fermentador cuadrado ${ }^{(14)}$ ) con capacidad de $2 \mathrm{~kg}$ aproximadamente, con perforaciones de o,4 $\mathrm{cm}$ de diámetro a los costados y en el fondo, y secador solar.

Equipos: estufa, incubadora con termostato, refrigeradora, molino de cuchilla (Mouline ${ }^{\circledast}$ ), balanza analítica, balanza de precisión, selladora, potenciómetro, licuadora, agitador magnético, equipo de titulación, guillotina, colorímetro Minolta ${ }^{\circledR} \mathrm{CR}-400$.

Reactivos: solución de hidróxido de sodio o, $1 \mathrm{~N}$, biftalato ácido de potasio, fenoftaleina, agua destilada.

\section{Procedimiento}

Selección de mazorcas: se separaron frutos putrefactos, con daños físicos, dañados por insectos, germinados, etc. con el fin de obtener semillas sanas que fermenten adecuadamente y permitan obtener un producto final de alta calidad.

Quiebre: se realizó con la ayuda de un cuchillo, el cual parte a la mazorca transversalmente con cuidado de no dañar los granos de cacao en baba.

Desgrane: se extrajo manualmente el cacao baba de la mazorca para hacerlo fermentar, se separaron las raicillas y los granos pegados para evitar la formación de granos múltiples que dificulten el secado. 
Fermentación: se colocó el cacao en baba en las cajas, que fueron tapadas con sacos de yute para impedir la liberación de calor al exterior, finalmente fueron puestas en una incubadora a temperatura regulada de $40 \pm 1^{\circ} \mathrm{C}$. Se realizó el mismo tratamiento para ambos tiempos de cosecha. En el transcurso de la fermentación, cada 24 horas se realizaron remociones de la masa con el fin de airear, permitir la fermentación acética y lograr que la masa alcance una temperatura homogénea ${ }^{(15,16)}$. El tiempo total de fermentación fue de tres días.

Secado: se hizo por la tarde en un mismo día. Los granos de cacao fueron expuestos al sol, extendiendo la masa sobre un secador solar portátil formando una capa de un centímetro de espesor. Los granos fueron colocados al sol en las horas con mayor brillo solar y luego guardados en un lugar seco durante la noche ${ }^{(17)}$. Durante el secado se realizaron remociones de la masa con el fin de facilitar la remoción del agua y realizar un secado homogéneo. El secado se dio por finalizado cuando la humedad fue de aproximadamente $8 \%{ }^{(11)}$, lo que tomó cinco días.

Control: Se realizó en el último día de secado, quinto día.

\section{Determinación de parámetros físicos en cada remoción en el proceso post cosecha}

Fermentación: se registró la temperatura de la masa, grosor del grano (de tres unidades experimentales a los que se les extraían los mismos tres granos de cacao previamente identificados), $\mathrm{pH}$ de testa y cotiledón -la testa fue separada del cotiledón para medir sus respectivos $\mathrm{pH}$ según AOAC 970.21, 2005 ${ }^{(18)}$-yel color del granoporunidad experimental.

Secado: Se registraron temperatura y humedad relativa ambiental, espesor, humedad según AOAC 931.04, $2005^{(18)}$ y color del grano por unidad experimental al inicio y al final del día de secado.

Determinación colorimétrica: El color de los granos de cacao fue controlado durante todo el proceso de beneficio. Las medidas del color fueron tomadas de tres unidades experimentales, a las que se extraían tres granos de cacao al azar que fueron cortados en forma longitudinal ${ }^{(19)}$ para apreciar el estado interno de cada grano y calificarlo ${ }^{(20)}$. El promedio de lectura de las nueve muestras fue tomada en cuenta para la comparación. Las lecturas $L^{*}, a^{*}$ y $b^{*}$ fueron registradas por el colorímetro Minolta ${ }^{\circledR}$ CR-400. Los cambios de color $\Delta E^{*}$ se calcularon por la ecuación ${ }^{(12)}$ :

$$
\Delta E^{*}=\left[\left(\Delta L^{*}\right)^{2}+\left(\Delta a^{*}\right)^{2}+\left(\Delta b^{*}\right)^{2}\right]^{1 / 2}
$$

Análisis estadístico: se midió la media de cada unidad experimental en el color $\left(L^{*}, a^{*}\right.$ y $\left.b^{*}\right)$ al inicio y al final de cada etapa de beneficio (fermentación y secado) para conocer su significancia. Posteriormente, se aplicó un diseño completamente al azar (DCA) $(p<0,05)$ para determinar diferencias de variación del color $\left(\Delta E^{*}\right)$ en ambos tiempos de cosecha (dos tratamientos), tres unidades experimentales y tres repeticiones por unidad experimental, usando el análisis de varianza ANOVA.

\section{RESULTADOS}

Beneficio del Cacao: se cosecharon mazorcas maduras del Cultivar Nativo de Piura con 10 surcos (figura 1), para el primer tiempo de cosecha 64 unidades con 5004,4 g de cacao en baba y, para el segundo tiempo, 70 unidades con $5709,2 \mathrm{~g}$, las que fueron distribuidas equitativamente en los tres cajones fermentadores cuadrados. El secado para el primer tiempo de cosecha se inició con 4170,9g de cacao y 59,60\% de humedad (en base húmeda) terminando con 2199,5 g con 9,3\% de humedad (en base húmeda), con 44,0\% de rendimiento; para el segundo tiempo de cosecha se inició con 4648,8 g de cacao con $65,3 \%$ de humedad (en base húmeda), reduciendo hasta $2087,7 \mathrm{~g}$ con $6,0 \% \mathrm{de}$ humedad (en base húmeda), con 36,6\% de rendimiento.

Determinación de parámetros físicos en cada remoción en el proceso post cosecha: los resultados, en los dos tiempos de cosecha para la fermentación del cacao en baba, expresados como temperatura $\left({ }^{\circ} \mathrm{C}\right)$, grosor $(\mathrm{mm})$ y pH de testa y cotiledón, se muestran en la tabla 1, observándose quelatemperaturadelamasaseincrementadesde $28^{\circ} \mathrm{Chasta}$ $42^{\circ} \mathrm{C}$ en promedio, el grosor no varía significativamente, el $\mathrm{pH}$ del cotiledón decrece significativamente. Asimismo, los resultados en los dos tiempos de cosecha para el secado, expresados como temperatura ambiental $\left({ }^{\circ} \mathrm{C}\right)$ y humedad relativa ambiental $(\%)$, grosor $(\mathrm{mm})$ y humedad del producto (en base húmeda, \%) se muestran en la tabla 2 , que permite apreciar que las condiciones ambientales de temperatura y humedad afectan el contenido de humedad del cacao. Las fotos del beneficio están en la figura 2.

Determinación colorimétrica: los componentes del color, luminosidad $\left(L^{*}\right)$ y cromaticidad $\left(a^{*}\right.$ y $\left.b^{*}\right)$, se registraron, y la variación del color $\left(\Delta E^{*}\right)$ se calculó en las etapas de beneficio (fermentación y secado solar) según el sistema CIELAB; ambos resultados se presentan en las tablas 3 y 4 para los dos tiempos de cosecha.

Análisis estadístico: se muestra en la tabla 5, en ANOVA. La variación de color para los componentes $a^{*}$ y $b^{*}$, así como para el cálculo $\Delta E^{*}$, fue significativa en el secado, siendo el Ftab $>$ 7,71.

\section{DISCUSIÓN}

En la figura 3 se muestra la variación del color durante el beneficio del cacao. Por etapas, se definen tres bloques "1", "2" $y$ “" 3 , que tienen los siguientes significados: 
“" es el día en el que se realizó el quiebre, por lo tanto sería el "día cero" del tratamiento aplicado a los granos de cacao; " 2 " es el día en que se dio fin a la fermentación para dar inicio al secado; y por último, "3" es el día en que se da por terminado el secado natural de los granos. Los valores de luminosidad $\left(L^{*}\right)$ varían teóricamente en el rango de o a 10o, mientras que los componentes de cromaticidad ( $a^{*}$ y $\left.b^{*}\right)$ lo hacen en un rango de $-60 \mathrm{a}+60$.

En el presente trabajo, los resultados se basan en dos tiempos de cosecha y un mismo tiempo de aguante en mazorca. El tiempo que el cacao en baba estuvo en la mazorca fueron los dos días que duró el traslado de las mismas desde su parcela en Piura al laboratorio en la Universidad Nacional Agraria La Molina en Lima.

Durante la fermentación, al ser granos tintos y blancos, los valores de $L^{*}$ iniciaron de 48,53 a 55,53 hasta 53,01 a 54,04; evidenciando variación no significativa ( $p>0,005)$; sin embargo, Emmanuel ${ }^{(21)}$ señala que durante la fermentación la luminosidad disminuye volviendo el grano más oscuro a medida que el proceso avanza, en su estudio se inició con un $L^{*}$ de 46,23 hasta 44,09 para granos de Ghana que no tuvieron tiempo de aguante en mazorcas.

Respecto al componente de cromaticidad $a^{*}$ para el color rojo, se observan valores de 13,90 a 11,39 hasta 11,03 a 12,29; evidenciando variación no significativa $(p>0,005)$. Emmanuel ${ }^{(21)}$, señala que este componente decrece progresivamente durante los primeros días de la fermentación de 12,10 a 8,69, lo que se puede atribuir a la descomposicióndeantocianinasquenormalmenteimparte el color púrpura a los granos poco o mal fermentados. El componente de cromaticidad $b^{*}$ comprende valores de 12,41 a 12,76 hasta 4,74 a 3,00 durante la fermentación, haciendo los granos menos amarillos; dichos valores evidencian variación no significativa $(p>0,005)$.

La combinación de $L^{*}, a^{*}$ y $b^{*}$, forma un color pardo iluminado.

A todo lo descrito anteriormente, Ortiz ${ }^{(22)}$, señala que el oscurecimiento de los granos durante el proceso fermentativoesproducidoporlahidrólisisdelasantocianinas y la posterior oxidación de las agliconas resultantes a compuestos quinónicos, los cuales contribuyen al color pardo propio del cacao fermentado. Por otra parte, afirma que el cambio a este color difiere entre los tipos de grano, por eso en este estudio los resultados son una referencia del comportamiento del Cultivar Nativo de Piura.

Los parámetros físicos en la fermentación indican que la temperatura de la masa se incrementó desde $28^{\circ} \mathrm{C}$ hasta $42^{\circ} \mathrm{C}$ en promedio y el $\mathrm{pH}$ del cotiledón disminuyó de 6,52 hasta 5,84 en promedio al tercer día de fermentado, siguiendo la misma tendencia reportada por Rodríguez ${ }^{(3)}$ acerca del comportamiento de los compuestos volátiles y no volátiles en los granos de cacao; en sus resultados el pH del grano disminuyo de 6.4 a 4.5 al octavo día de fermentación.

Durante el secado los componentes del color varían (tablas 3 y 4 , figura 2); la luminosidad $L^{*}$ disminuye significativamente $(p<0,05)$, haciendo que la combinación $L^{*}, a^{*}$ y $b^{*}$ forme un color pardo más oscuro. La variación se debería a la formación de pigmentos marrones producidos por reacciones decondensación proteína-quinona ocurridas después de la oxidación enzimática de polifenoles, tales como leucocianidinasy epicatequinas ${ }^{(22)}$. Al secar los granos fermentados exponiéndolos al sol, $a^{*}$ aumentó $(8,90$ y 12,14 hasta 15,94 y 13,44; valores más rojos) y $b^{*}$ disminuyó (11,86 y 5,55 hasta 2,14 y 8,15 ; valores menos amarillos), similares resultados a los de Nogales ${ }^{(23)}$, que evidenció aumento de $a^{*}(6,30$ a 7,71$)$ y disminución de $b^{*}(7,78$ a 5,78). La figura 2, muestra fotos de los granos de cacao, que se han oscurecido principalmentedebidoa lavariación de $L^{*}$, inclusiveaquellos granos blancos se volvieron cremas o pardos.

Los valores físicos durante el secado muestran que la temperatura ambiental en promedio se inició en $26,6^{\circ} \mathrm{C}$ subió hasta un máximo de $34,6^{\circ} \mathrm{C}$ y terminó en $25,3^{\circ} \mathrm{C}$, llegando el grano de cacao a una humedad promedio de $7,7 \%$.

Al final del beneficio, los valores $L^{*}(31,36$ y 34,76$)$ fueron más oscuros, mientras que para $a^{*}(15,94$ y 13,44$)$ fueron más rojos en comparación con otros estudios $(22,23,9)$; sin embargo los valores de $b^{*}(2,14$ y 8,15$)$ son similares a Nogales ${ }^{(23)}$ y Ortiz ${ }^{(9)}$.

Los cambios de color $\left(\Delta E^{*}\right)$ en los cotiledones de los granos de cacao durante la fermentación, indican el grado de fermentación ${ }^{24,25)}$, por lo que son importantes para definir la calidad del producto final. Sin embargo, al ser un método subjetivo y no consistente ${ }^{(26)}$, se empleó el sistema CIELAB, como se aprecia en las tablas 3 y 4 , los valores de $\Delta E^{*}$ en la fermentación son similares para los dos tiempos de cosecha $(15,6$ y 12,9), mientras que en el secado, el valor del primer tiempo fue mayor $(31,1$ y 17,4$)$, resultado atribuible a las diferentes condiciones ambientales durante los procesos. Esta diferencia se evidencia es sginificativa según el análisis de varianza $(p<0,05)$.

\section{CONCLUSIONES}

Se logró conocer los valores triestímulo que componen el color durante el beneficio de las mazorcas de cacao del Cultivar Nativo procedente de Piura, utilizando el sistema de evaluación CIELAB.

Se pudo comprobar que los parámetros de color como luminosidad $\left(L^{*}\right)$, componente de cromaticidad rojo-verde $\left(a^{*}\right)$ y amarillo-azul $\left(b^{*}\right)$, no varían durante 
la fermentación del grano decacao. Duranteel secadoel parámetro físico del color $L^{*}$ decrece significativamente $(p<0,05)$. La variación de color $\left(\Delta E^{*}\right)$ en el secado depende de la condiciones ambientales.

Se demostró que en el proceso de beneficio del cacao, los valores de los componentes de color $L^{*}(48,53$ y 55,53 hasta 31,36 y 36,74$)$ y $b^{*}(12,41$ y 12,76 hasta 2,14 y 8,15 ) disminuyen, sin embargo $a^{*}$ (13,90 y 11,39 hasta 15,94 y 13,44 ) aumenta, dando como resultado granos oscuros y de color pardo para el cacao Cultivar Nativo de Piura.

\section{REFERENCIAS BIBLIOGRÁFICAS}

1. Sandoval, A. Evaluación de fermentaciones de cacao clon Catongo y comparación con dos clones. Universidad EARTH. Costa Rica; 2009.

2. Schwan R, Wheals A. The microbiology of cocoa fermentation and its role chocolate quality. Critical Reviews in Food Science and Nutrition. 2004; 44(4): 205-21.

3. Rodríguez J, Escalona H, Orozco I, Lugo E, Jaramillo M. Dynamics of volatile and non-volatile compounds in cocoa (Theobroma cacao L.) during fermentation and drying processes using principals components analysis. Food Research International 2011; 44(1): 250-8.

4. Afoakwa E, Paterson A, Fowler M, Ryan A. Flavor formation and character in cocoa and chocolate: a critical review. Crit Rev Food Sci Nutr. 2008; 48(9): 840-57.

5. Braudeau, J. El Cacao. $1^{\text {ra }}$ ed. Barcelona: Blume; 1970

6. Ortiz L, Rovedas G, Graziani L. Influencia de varios factores sobre índices físicos del grano de cacao en fermentación. Agronomía Tropical. 2009; 59(1): 81-8.

7. Contreras C, Ortiz L, Graziani L, Parra P. Fermentadores para cacao usados por los productores de la localidad de Cumboto, Venezuela. Agronomía Tropical. 2004; 54(2): 219-32.

8. Rivera R, Mecías F, Guzmán A, Peña M, Medina H, Casanova Ly col. Efecto del tipo y tiempo de fermentación en la calidad física y química del cacao (Theobroma cacao L.) tipo nacional. Ciencia y Tecnología. 2012 5(1): 7-12.

9. Ortiz L, Camacho G, Graziani L. Efecto del secado al sol sobre la calidad del grano fermentado de cacao. Agronomía Trop. 2004 54(1):31-43.

10. Hii CL, Law CL, Cloke M. Modeling using a new thin layer drying model and product quality of cocoa. Journal of Food Engineering. 2009; 9o(2): 191-8.

11. INDECOPI, NTP ISO 2451. Granos de cacao: Especificaciones. $3^{\text {ra }}$ ed. Lima; 2011.

12. Jiménez A, Gutiérrez G. Color. En: Alvarado J, Aguilera J, editores. Métodos para medir propiedades físicas en industrias de alimentos. Zaragoza: Acribia; 2001. pp. 325-46.

13. García LF. Catálogo de Cultivares de Cacao del Perú. $\mathbf{1}^{\text {ra }}$ Reimpresion. Ministerio de Agricultura. Lima; 2012.

14. Portillo E, Graziani L, Betancourt E. Efecto de los tratamientos post-cosecha sobre la temperatura y el índice de fermentación en la calidad del grano del cacao criollo
Porcelana (Theobroma cacao L.) en el sur del lago Maracaibo. Revista Facultad Agronomía 2005; 22(4):394-406.

15. Zambrano A, Romero C, Gómez A, Ramos G, Lacruz C, Brunetto $\mathrm{M}$ y col. Evaluación química de precursores de aroma y sabor de cacao criollo merideño durante la fermentación en dos condiciones edafoclimáticas. Agronomía Trop. 2010; 6o(2): 211-9.

16. Álvarez C, Tovar L, García H, Morillo F, Sánchez P, Girón C y col. Evaluación de la calidad comercial del grano de cacao (Theobroma cacao L.) usando dos tipos de fermentadores. Revista Científica UDO Agrícola. 2010; 10(1): 76-87.

17. Zambrano A, Gómez A, Ramos G, Romero C, Lacruz C, Rivas E. Caracterización de parámetros físicos de calidad de almendras de cacao criollo, trinitario y forastero durante el proceso de secado. Agronomía Tropical. 2010; 6o(4):389-96.

18. A.O.A.C. Official Methods of Analysis of AOAC International. Volume II. 18 ${ }^{\text {th }}$ ed. Maryland: AOAC; 2005.

19. INDECOPI. NTP ISO 1114: 2006. Granos de Cacao. Prueba de corte. $3^{\text {ra }}$ ed. Lima; 2011.

20. Moreno LJ, Sánchez JA. Beneficio del Cacao. Tegucigalpa: Fundación Hondureña de Investigaciones Agrícolas. 1989. Fascículo $\mathrm{N}^{\circ}$ 26: 26.

21. Emmanuel O, Jennifer Q, Agnes S, Jemmy S, Firibu K. Influence of pulp-preconditioning and fermentation on fermentative quality and appearance of Ghanaian cocoa (Theobroma cacao) beans. International Food Research Journal. 2012; 19(1): 127-33.

22. Ortiz L, Graziani L, Rovedas G. Influencia de varios factores sobre características del grano de cacao fermentado y secado al sol. Agronomía Trop. 2009; 59(2): 119-27.

23. Nogales J, Graziani L, Ortiz L. Cambios físicos y químicos durante el secado al sol del grano de cacao fermentado en dos diseños de cajones de madera. Agronomía Trop. 2006; 56(1): 5-20.

24. Del Boca, C. Cocoa beans: quality requirements and methods of assessment. Rev Int Chocolaterie. 1962; (17): 218-21.

25. Shamsuddin, SB; Dimick, PS. Qualitative and quantitative measurements of cacao bean fermentation, in Proceedings of cocoa biotechnology. USA. Department of Food Science, Penn State University, Pennsylvania: Penn State University; 1986. pp. 55-78.

26. Ilangantileke, SG; Wahyudi, T; Bailon, MG. Assessment methodology to predict quality of cocoa beans for export. Journal of Food Quality. 1991; 14(6): 481-496.

Manuscrito recibido el: 24/11/2015

Aceptado para su publicación el: 20/04/2016

\section{Correspondencia:}

Nombre:

Gabriela Cristina Chire Fajardo Jorge Hilario Guzmán Bautista

Dirección: Av. Los Quechuas 123 Salamanca Lima, Perú. Jr. Punto 1002. Lima, Perú.

e-mail: $\quad$ gchire@lamolina.edu.pe jguzmanb@unmsm.edu.pe 